ارزيابى مدلهاى WOFOST AquaCrop و CropSyst

\author{
عملكرد جغندرقند تحت شرايط كم آبيارى \\ نيازعلى ابراهيمى ياك "و اصلان احدرنزاد"

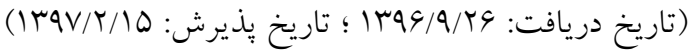

جكيده

جغندرقند يكى از محصولات مهم زراعى است و عملكرد آن بهميزان آب مصرفى وابسته است. بهدليل عدم امكان ارزيابى كليسه گزينسه آهاى

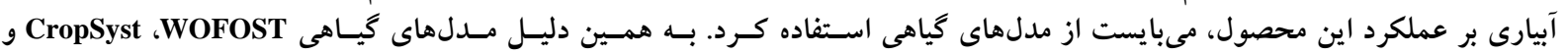

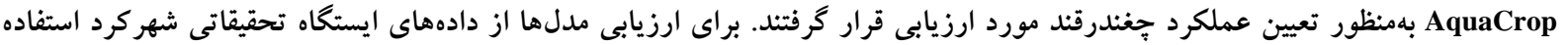

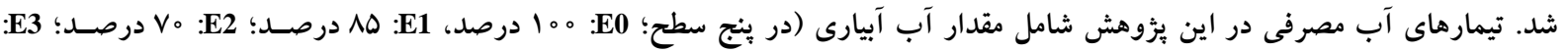

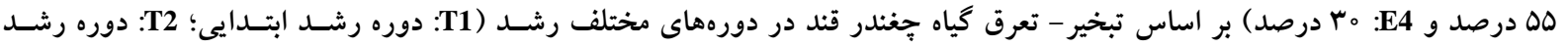

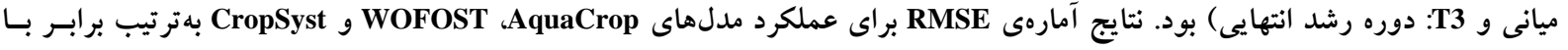
هV/OV

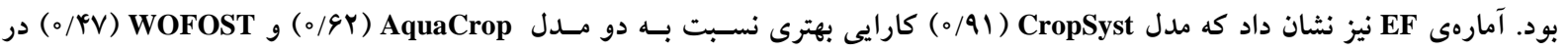
تعيين عملكرد داشت. بر اساس اين نتايج، مدل CropSyst، دقت بيشترى نسبت به دو مدل ديكرى دادئ دارد.

وازههاى كليدى: مدل آب محور، مدل تابش محور، مدلسازى گياهى

ا. بخش آبيارى و فيزيك خاك، مؤسسه تحقيقات خاك و آب، سازمان تحقيقات، آموزش و ترويج كشاورزى، كرج، ايران r. كروه علوم و مهندسى آب، واحد اهواز، دانشخاه آزاد اسلامى، اهواز، ايران

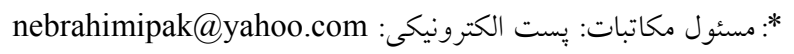




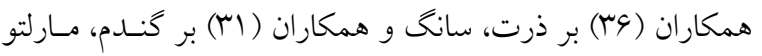

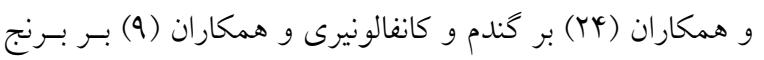

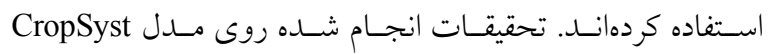

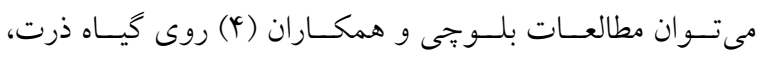

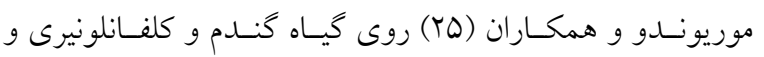

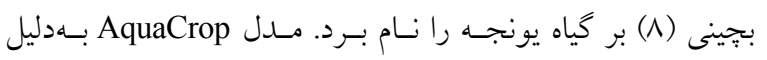

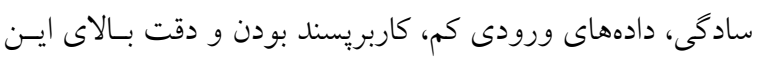

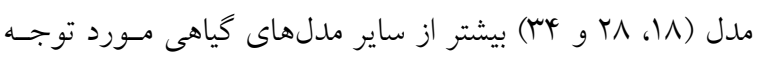

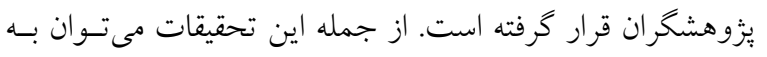

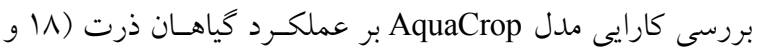

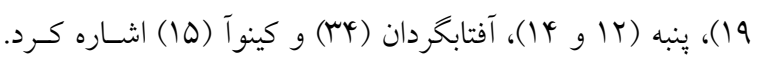

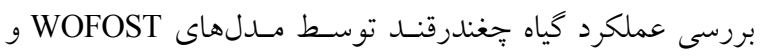

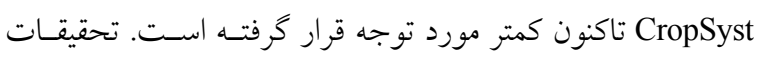

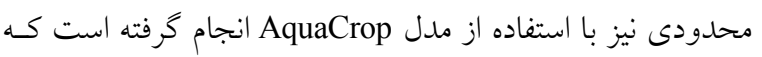

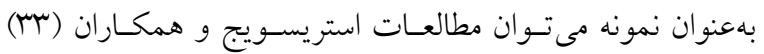

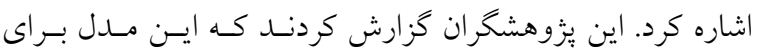

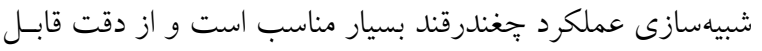

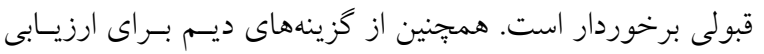

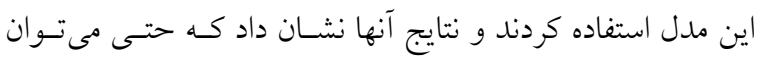

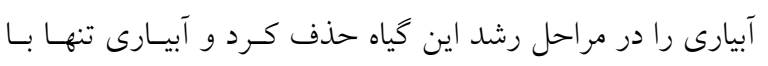

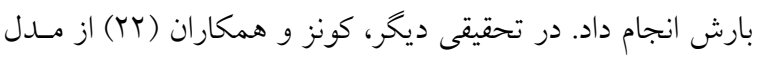
AquaCrop استفاده كردند. نتايج تحقيقـات نشـان داد كـه ايـن مــل كـارايى مطلوبى براى برنامهريزى مصـرف آب در كشـاورزى در شـرايط تحت تنش آبى در آفريقاى جنوبى داشت. عليشـيرى و همكــاران

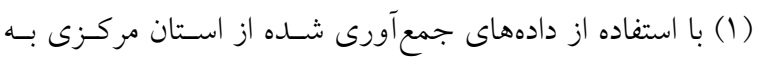

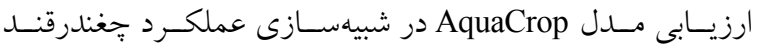

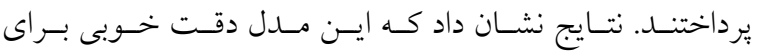

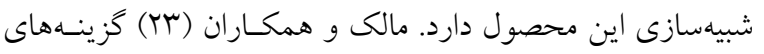

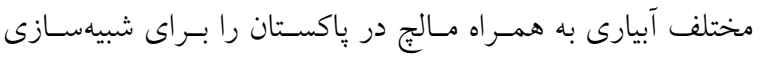

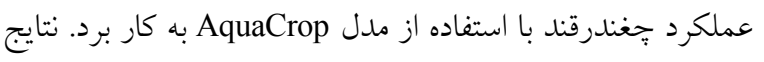

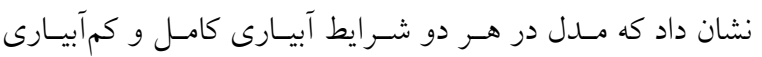

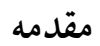
جغنندرقند بهدليل توليد قند و شكر، خــوراك دام، مـلاس اهميـت

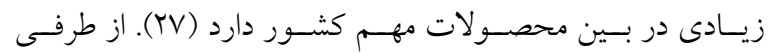

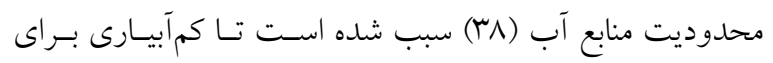
توليد محصولات كشاورزى، از جمله جِغندرقند، بهعنوان يكى از

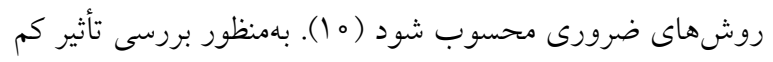

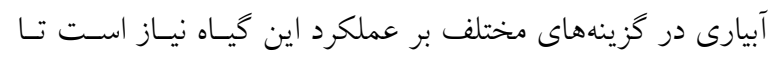
آزمايشهاى مزرعهاى متعددى انجام شود. ليكن اين عمل مستلزم

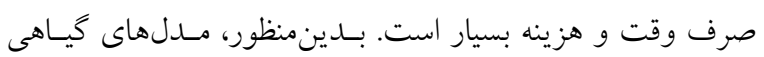

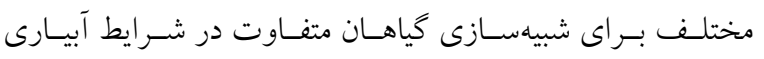

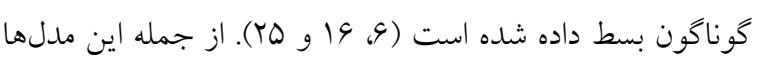

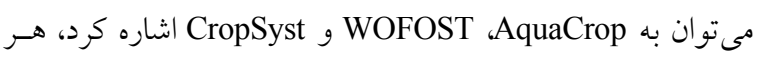

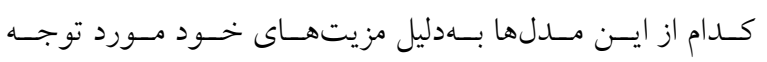

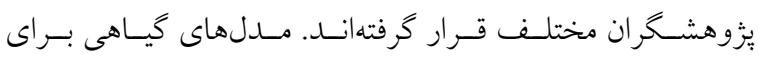

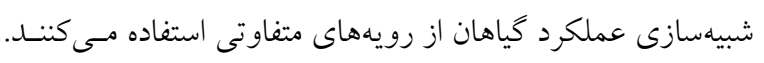

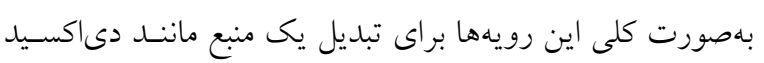

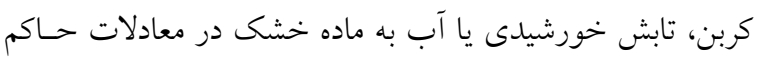

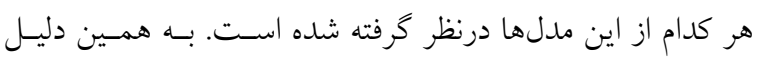

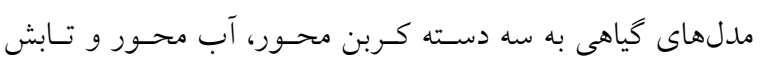

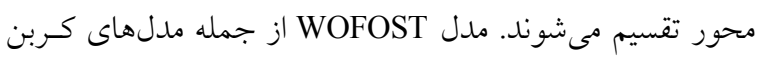

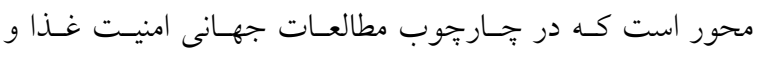

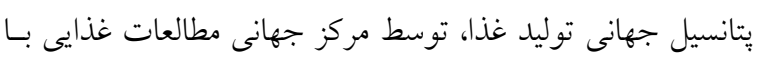

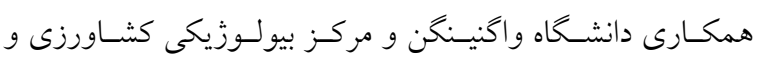

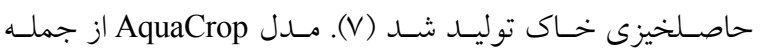
مدلهاى آب محور است كه توسط سازمان خوار و بار كشاورزى

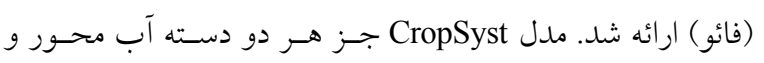
تابش محور محسوب مىشود و توسط اسـتوكل و نلسـون (Tr)

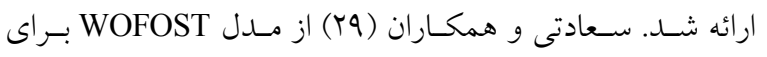
شبيهسازى عملكرد دو رقم برنج تحت رزيمهاى مختلف آبيـارى

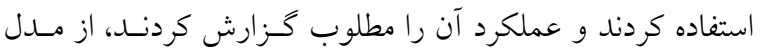

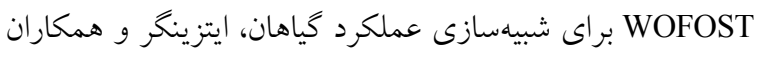

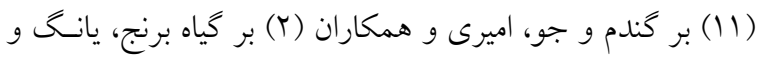


جدول ا. خصوصيات فيزيكى وشيميايى خاك مزرعه

\begin{tabular}{|c|c|c|c|c|c|c|c|c|c|c|c|}
\hline يتاسيم & فسفر & كل & كربن & درصد & $\mathrm{EC}$ & $\mathrm{pH}$ & رطوبت دريت & 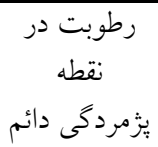 & ظخصوص جرم & بافت & عمق \\
\hline \multicolumn{2}{|c|}{ ppm } & $(\%)$ & $(\%)$ & - & $(\mathrm{dS} \mathrm{m})^{-}$ & - & \multicolumn{2}{|c|}{$\left(\mathrm{cm}^{r} \mathrm{~cm}^{-r}\right)$} & $\left(\mathrm{g} \mathrm{cm}^{-r}\right)$ & & $(\mathrm{cm})$ \\
\hline rAY & $1 / 10$ & $V_{0}$ &.$/ 00$ & 40 & $\circ / \pi \Delta$ & $\mathrm{N} / \circ \mathrm{V}$ & $0 / T Y$ & $0 / 1 Y$ & $1 / \pi y$ & سيلتىرسى & o-ro \\
\hline rar & $V / V$ & $V T$ & $0 / 4 \wedge$ & Or & (T/ & $\mathrm{N} / \circ \mathrm{V}$ & $0 / Y Y$ & $0 / 11$ & I/NA & لومىشنى & $\mu_{0-9}$ \\
\hline
\end{tabular}

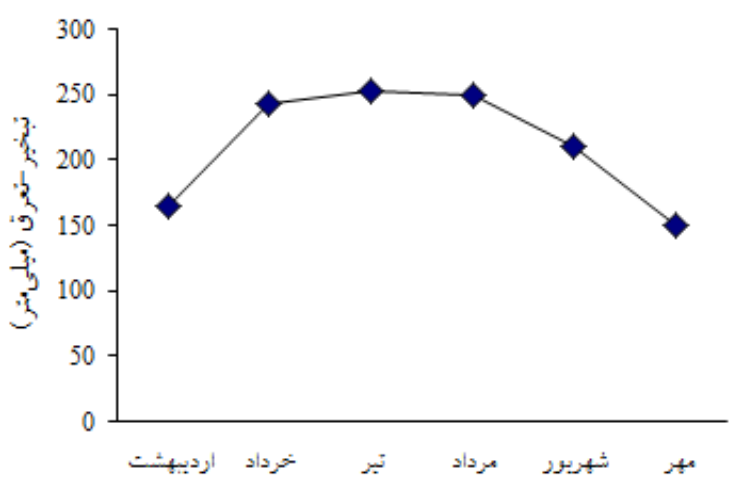

os

شكل 1. نتايج لايسى مترى تبخير - تعرق گياه جغندر قند

درصد، E1: هم درصد؛ E2: • V درصد؛ E3: هه درصسد و E4: درصد) تبخير - تعرق گياه جِغندرقند و در دورههاى مختلف رشد (T1): دوره رشد ابتدايى؛ T2: دوره رشد ميانى و T3: انتهـاى دوره

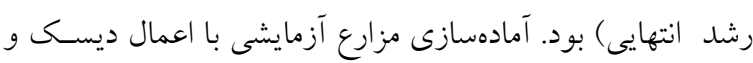

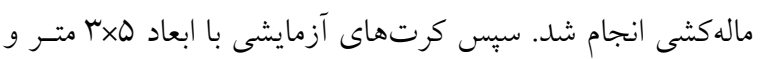
با فواصل T/D متر آماده شدند. مشخصات خاك مزرعه در جدول

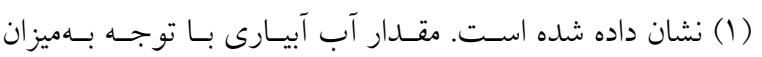
تبخير - تعرق واقعى كيـاه جِنــدر قنـــ تعيسين و توسط كنــور اندازه گيرى مىشد. تبخير - تعرق گياه نيز با ايجاد يـى لايسـيمتر زهكشدار در كنار كرتهاى آزمايشسى مشـخص مى مشيسد. نتسايج بهدست آمده از تبخير - تعرق در شكل (1) نشان داده شده اسـت. در انتهاى فصل رشد نيز برداشت با درنظر كـرفتن اثـر حاشـيهاى

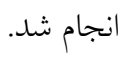
مدل AquaCrop براى شبيهسازى عملكرد كيـاه رابطـه (1) از بيوماس شبيهسازى شده شده رابطه (Y) اسـتفاده مى كنـد. در ايسن مدل تعرق بهعنوان مؤلفه اصلى توليد ماده خشى محسوب شــه
ملايم از دقت بالايى برخوردار بود.

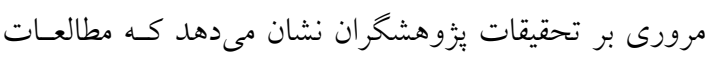

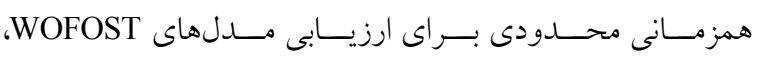
CropSyst شده است. به همين دليل، تحقيق حاضر بـهنظور ارزيـابى ايسن

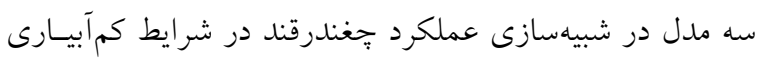

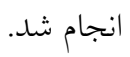

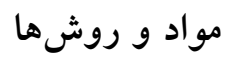

در اين ئزوهش سـه مسدل WOFOST AquaCrop و CropSyst بهمنظور شبيهسازى عملكرد جِغندر قند مورد ارزيابى قرار گرفتند. بـــينمنظور دادههـاى دو فصـل كشـت برداشـت شـــه ايستخاه

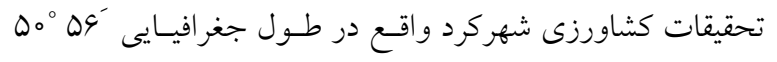

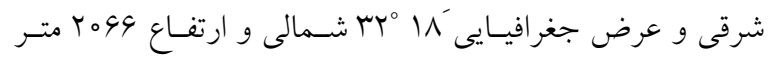
بالاتر از سطح مورد استفاده قرار گرفت. تيمارهاى مـورد اسـتفاده

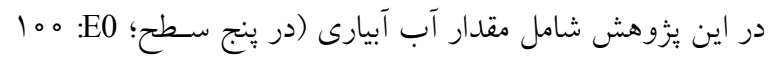


كه در اين رابطه، DW ميزان رشد، A ميزان ناخـالص جـــب، ميزان تعرق نخهارى و R R

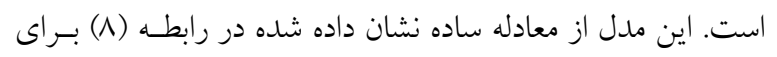
تعيين ميزان جذب و رشد كياه در شرايط كمآبيارى استفاده مى كند: $\mathrm{A}=\frac{\mathrm{T}_{\mathrm{a}}}{\mathrm{T}_{\mathrm{p}}} \times \mathrm{A}_{\mathrm{p}}$

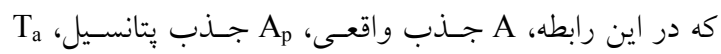

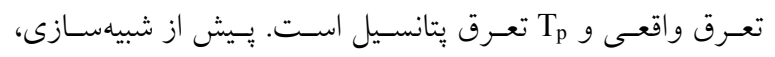

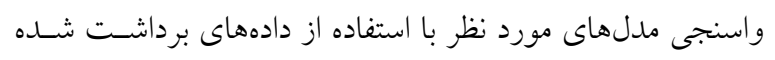

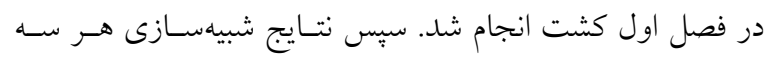
مدل نيز با دادههاى برداشت شده فصل دوم كشت مقايسه شـدند.

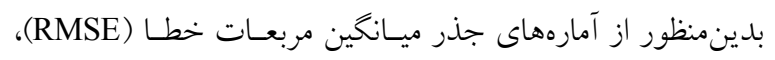

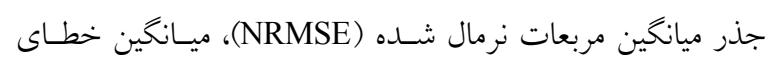

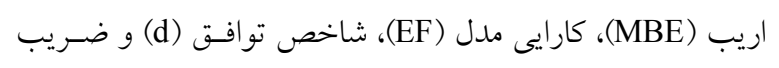

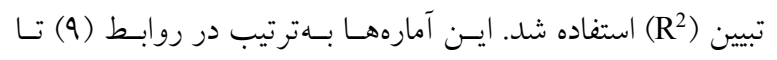

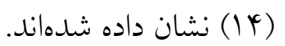
RMSE $=\sqrt{\frac{\sum_{i=1}^{n}\left(P_{i}-O_{i}\right)^{r}}{n}}$

NRMSE $=\frac{\sqrt{\frac{\sum_{\mathrm{i}=1}^{\mathrm{n}}\left(\mathrm{P}_{\mathrm{i}}-\mathrm{O}_{\mathrm{i}}\right)^{r}}{\mathrm{n}}}}{\overline{\mathrm{O}_{\mathrm{i}}}}$

MBE $=\frac{\sum_{i}^{n}\left(P_{i}-O_{i}\right)}{n}$

$E F=1-\frac{\sum_{i=1}^{n}\left(P_{i}-O_{i}\right)^{r}}{\sum_{i=1}^{n}\left(O_{i}-\bar{O}\right)^{r}}$

$d=1-\frac{\sum_{i=1}^{n}\left(P_{i}-O_{i}\right)^{r}}{\sum_{i=1}^{n}\left(\left|P_{i}\right|+\left|O_{i}\right|\right)^{r}}$

$\mathrm{R}^{r}=\frac{\left(\sum\left(\mathrm{P}_{\mathrm{i}}-\overline{\mathrm{P}}\right)\left(\mathrm{O}_{\mathrm{i}}-\overline{\mathrm{O}}\right)\right)^{r}}{\sum\left(\mathrm{P}_{\mathrm{i}}-\overline{\mathrm{P}}\right)^{r} \sum\left(\mathrm{O}_{\mathrm{i}}-\overline{\mathrm{O}}\right)^{r}}$
و توسط رابطـهـ (r) از تفكيـى دو جـز تبخيــر و تعـرق محاسـبه مىشود.

$\mathrm{Y}=\mathrm{B} \times \mathrm{HI}$

$\mathrm{B}=\mathrm{WP}^{*}\left[\frac{\mathrm{Tr}_{\mathrm{i}}}{\mathrm{ET}_{\mathrm{o}, \mathrm{i}}}\right]$

$\mathrm{T}_{\mathrm{r}}=\mathrm{K}_{\mathrm{S}} \times \mathrm{CC} \times \mathrm{K}_{\mathrm{c}} \times \mathrm{ET}$ 。

كه در اين روابط، Yملكرد، HI شاخص برداشـت، B بيومـاس

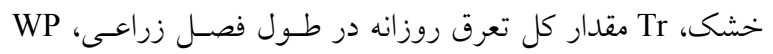

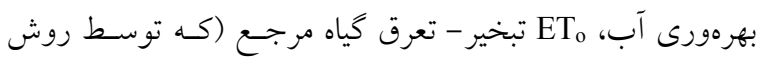

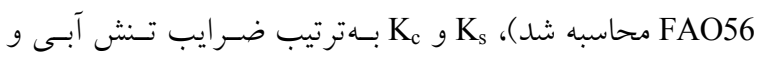

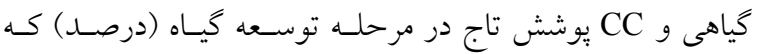
توسط رابطه (Y) محاسبه مىشود (YN).

$\mathrm{CC}=\mathrm{CC}_{\circ} \times \mathrm{e}^{\mathrm{CGC} . \mathrm{t}}$

در اين رابطه: CC يوشش تاج اوليه (درصد)، CGC ضـريب رشد يوشش تاج (عكس روز) و t زمان (روز) است.

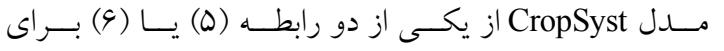
شبيهسازى توليد بيوماس استفاده مى كند. اين دو رابطه بـر اسـاس دو رويه اساسى است كـه در مــل CropSyst بــراى شبيهسـازى

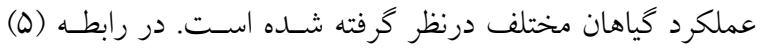
ميزان عملكرد بر اساس تابش جذب شده توسط گياه و در رابطهـ (9) مقدار عملكرد بر اساس تعرق شبيهسازى مى شودد.

$$
\mathrm{AGB}_{\text {IPAR }}=\mathrm{RUE} \times \mathrm{IPAR} \times \mathrm{T}_{\text {lim }}
$$

$\mathrm{AGB}_{\mathrm{T}}=\mathrm{T}_{\text {act }} \times \frac{\mathrm{BTR}}{\mathrm{VPD}}$

در اين رابطه، AGB و و AGBAR بيوماس گياه، RUE فاكتور

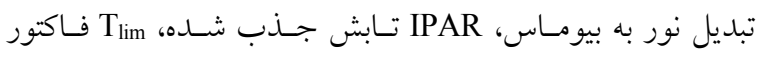

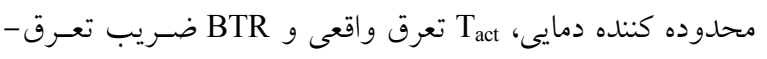

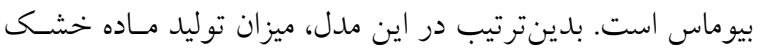

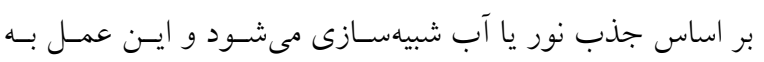
محدوديت يكى از اين دو فاكتور بستخى دارد.

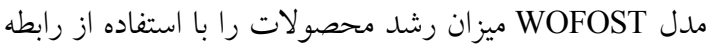
(V) بهدست مى آورد: (V) $\Delta \mathrm{W}=\mathrm{C}_{\mathrm{e}} \times\left(\mathrm{A}-\mathrm{R}_{\mathrm{m}}\right)$ 
WOFOST و CropSyst

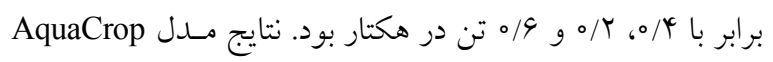

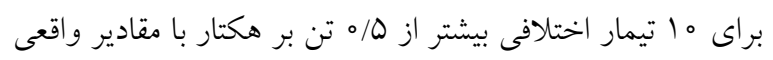

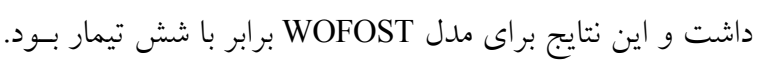

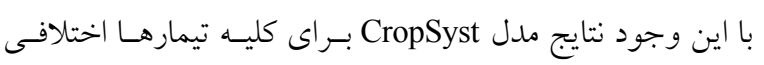

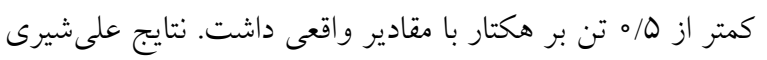

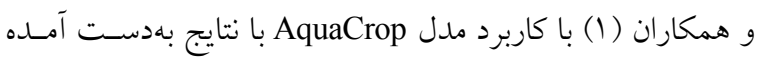

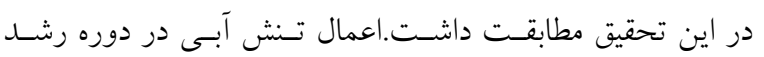

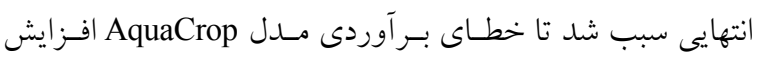

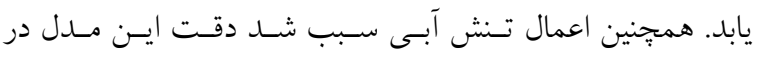

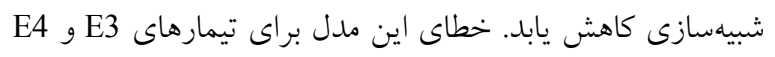

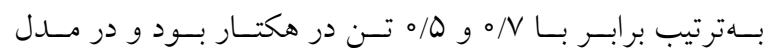

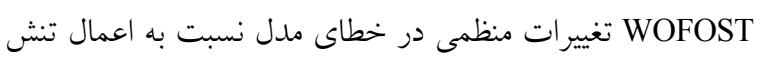

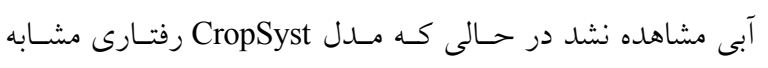
AquaCrop

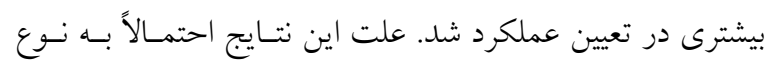

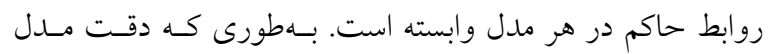
WOFOST

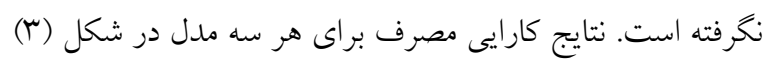

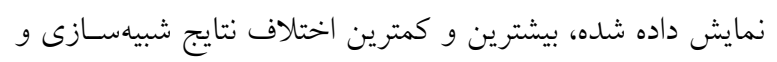

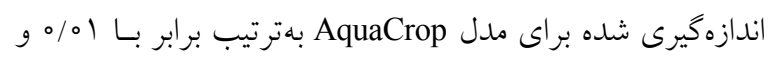

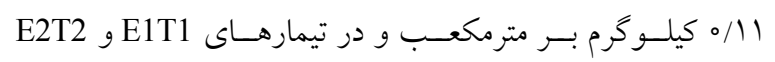

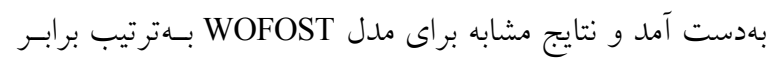

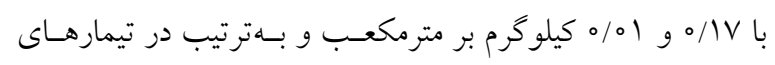

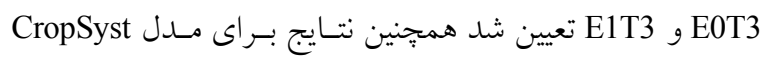

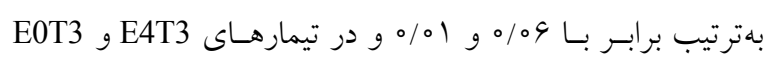

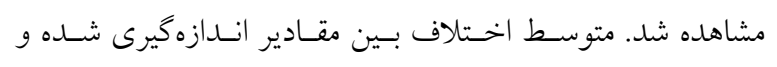

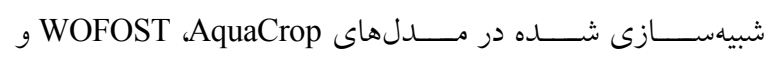
CropSyst

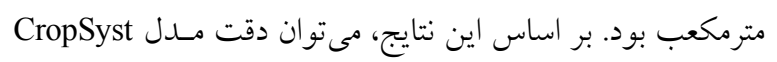

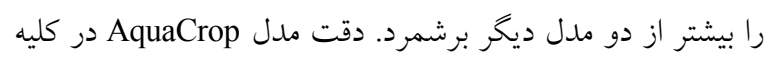

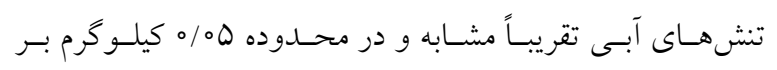

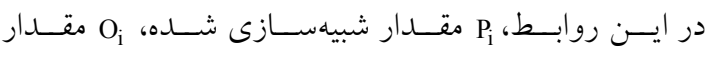

انسدازهيرى شـده،

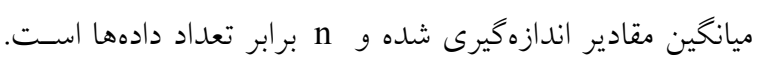

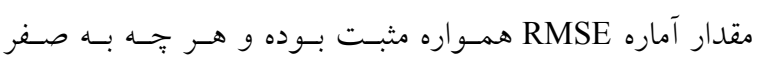

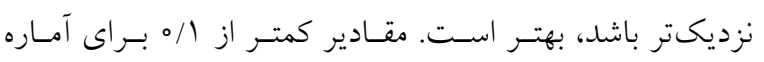

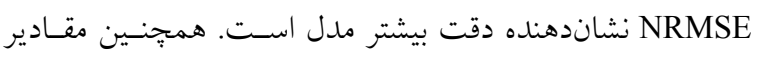

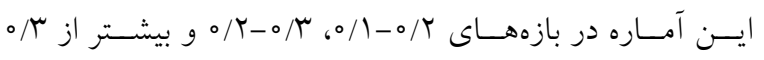

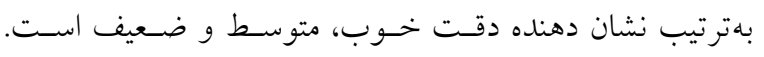

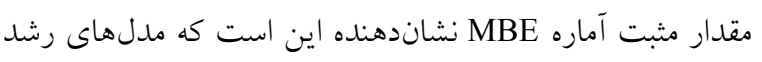

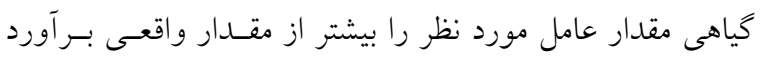

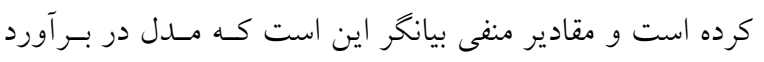

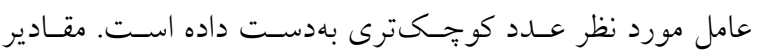

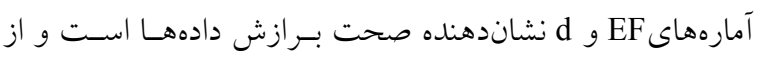
مقدار منفى بىنهايت در بدترين حالت تا يكى در زمهان بـرازش

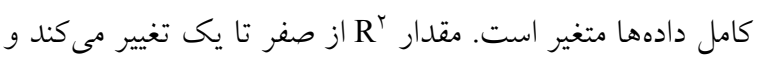

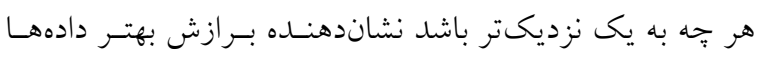

\section{نتايج و بحث}

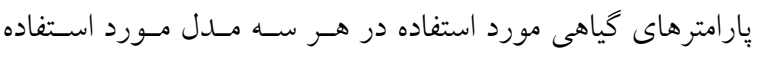

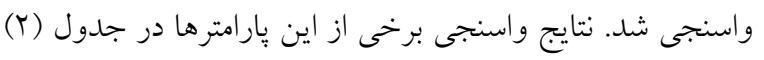

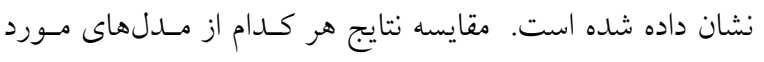

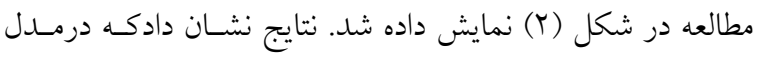
AquaCrop

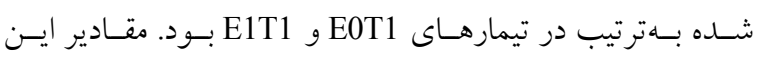

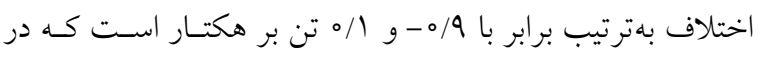

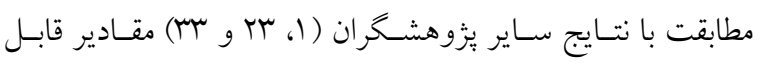
قبولى است، بيشترين و كمترين اختلاف مقادير شبيهسازى شده و

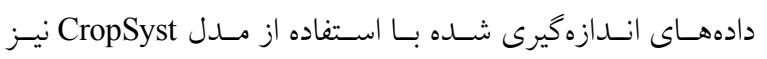
بلترتيب در تيمارهاى E4T3 و E0T3 بــر آورد شـــ ايسـن مقـادير

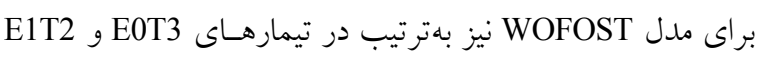

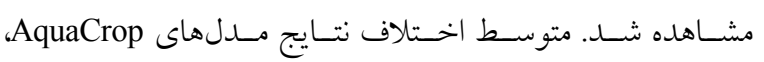


نشريه علوم آب و خاك (علوم و فنون كشاورزى و منابع طبيعى) / سال بيست و سه / شماره اول / بهار \هـ1

جدول r. مقادير عوامل گياهى مورد استفاده در مدلهاى مورد استفاده

\begin{tabular}{|c|c|c|c|}
\hline توضيح & واحد & مقدار & توضيح عامل \\
\hline \multicolumn{4}{|c|}{ مدل AquaCrop } \\
\hline ي بيش فرض & درجهسانتى گر اد & 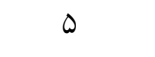 & دماى بِيه \\
\hline ي بيش فرض & درجه سانتى گراد & r。 & 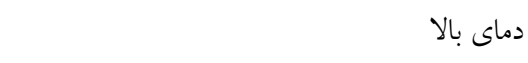 \\
\hline 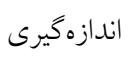 & كياه در هكتار & 100000 & 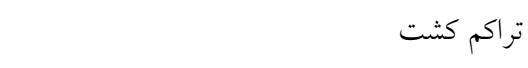 \\
\hline ي بيش فرض & د مرصد روز & $1 \% / 9$ & ضريب رشد كانويى \\
\hline ي بيش فرض & سانتى متر مربع & 0 & يوشش گياهى هر نهال هنخام جوانهزنى \\
\hline واسنجى & كرم بر متر مربع & $\mid y / r$ & بهرهورى آب نرمال شده \\
\hline واسنجى & درصد & $r / r$ & يوش ي كياهى اوليه \\
\hline و واسنجى & درصد & $\Lambda r$ & بيشينه رشد كانويى \\
\hline 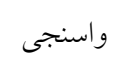 & - & $0 / 10$ & حد بالا ضريب تخليه آب خاك براى توسعه كياه \\
\hline 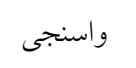 & - & $\circ / \Delta \Delta$ & حديايين ضريب تخليه آب براى توسعه گياه \\
\hline واسنجى & د مرصد روز & $1 Y / \circ$ & ضريب رشد يوشش \\
\hline واسنجى & 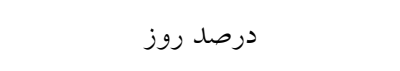 & $\Delta / r$ & ضريب كاهش يوشش \\
\hline 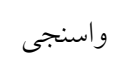 & د مرصد بر روز & $1 / 1$ & حداكثر ضريب كياهى براى تعرق \\
\hline \multicolumn{4}{|c|}{ مدل مO WOFOST } \\
\hline ي بيشفرض & درجهسانتى گر اد & r & دماى يُايين براى جوانهزنى \\
\hline واسنجى & - & $\circ-\circ, 0-\partial \varphi$ & ضريب خاموشى نور جذب شده \\
\hline واسنجى & كيلوگرم بر هكتار ساعت زول مربع & $0-0,0-\varphi \Lambda$ & كارايى مصرف نور براى يك برى \\
\hline 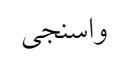 & 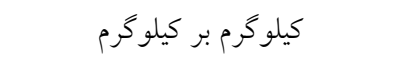 & $\circ / V Q$ & كارايى تبديل ماده جذب شده به برى \\
\hline 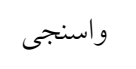 & كيلو گرم بر كيلو گرم & $\circ / \wedge \circ$ & كارايى ماده جذب شده به اركان ذخيرهاى \\
\hline 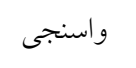 & كيلو گرم بر كيلو رُم & $\circ / V Y$ & كارايى ماده جذب شده به ريشه \\
\hline 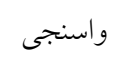 & كيلو گرم بر كيلو گرم & $\circ / 0 \mathrm{~V}$ & كارايى ماده جذب شده به ساقه \\
\hline و واسنجى & - & $1 / r$ & فاكتور تصحيح ميزان تعرق \\
\hline
\end{tabular}

مدل CropSyst

\begin{tabular}{|c|c|c|c|}
\hline و واسنجى & - & $1 / 01$ & ضريب تبخيرتعرق گياهى \\
\hline واسنجى & - & $\circ / 4$ & ضريب خاموشى نور \\
\hline و واسنجى & درجه سانتى گر اد & 0 & دماى يايه \\
\hline واسنجى & - & $1 / T \Delta$ & ضريب جذب نيتروزن \\
\hline واسنجى & متر & $1 / r$ & حداكثر عمق ريشه \\
\hline
\end{tabular}



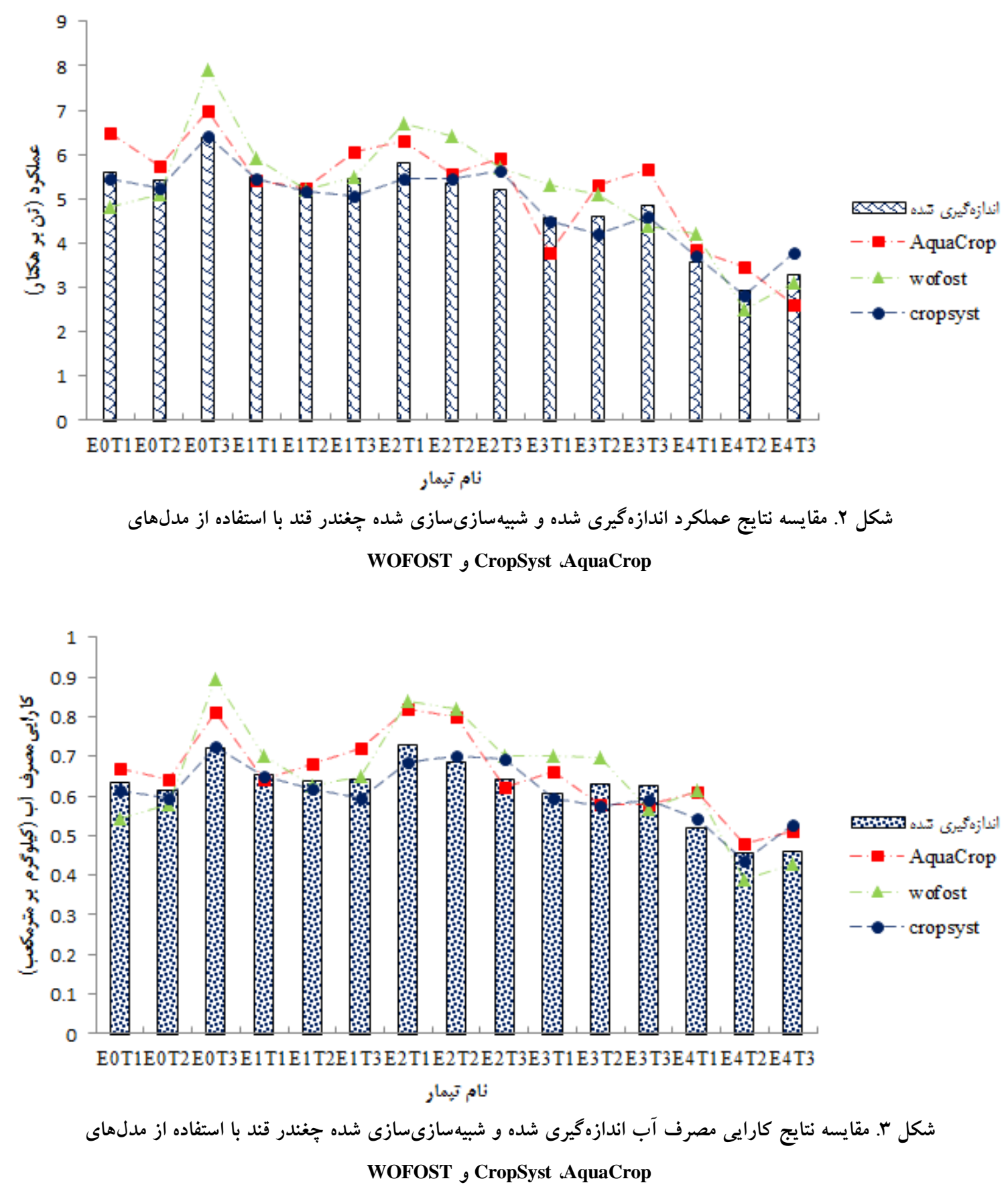

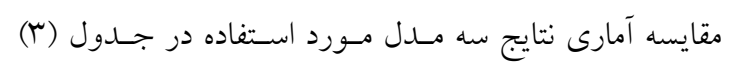

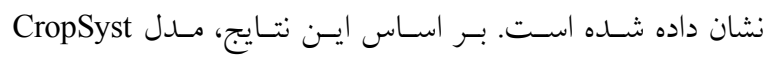

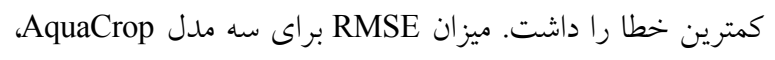
WOFOST ب CropSyst
مترمكعب بهدسـت آمـــ و تنهـا در تيمارهـاى تسنش E2 خطـاى

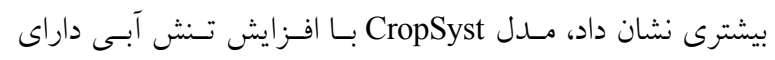

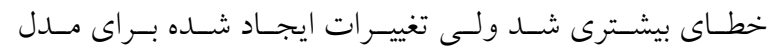

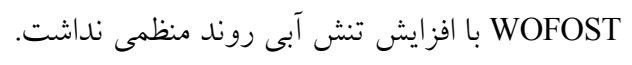


نشريه علوم آب و خاك (علوم و فنون كشاورزى و منابع طبيع) / سال بيست و سه / شماره اول / بهار شجr|

\begin{tabular}{|c|c|c|c|c|c|c|c|}
\hline $\mathrm{R}^{2}$ & $\mathrm{~d}$ & $\mathrm{EF}$ & MBE & NRMSE & RMSE & ن مام مدل & 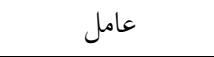 \\
\hline.$/ 09$ & $0 / 99$ & ०/9Y & $0 / 79$ & $\circ / 11$ & $\circ / \Delta V$ & AquaCrop & \\
\hline$\circ / V Q$ & $0 / 99$ &.$/ 91$ & $-0 / 09$ & $\% 00$ & $0 / T \varphi$ & CropSyst & عملكرد \\
\hline$\circ / V_{0}$ & $\circ / 99$ & $\circ / 4 V$ & $\circ / T \Delta$ & - (1/ & $0 / 9 \wedge$ & WOFOST & \\
\hline $0 / 94$ & $0 / 99$ & $0 / 4 q$ & \%/० & $0 / 09$ & 0109 & AquaCrop & \\
\hline $0 / 9 Y$ & $0 / 99$ & $\circ / \wedge \circ$ & $-0 / 01$ & $\circ / 00$ & ०/०r & CropSyst & كارايى مصرف آب \\
\hline $0 / 94$ &.$/ 99$ & $-0 / 19$ & ०/० & . & $\circ / \circ \wedge$ & WOFOST & \\
\hline
\end{tabular}

كنــدم و كانفـالونيرى و همكـاران (9) بـــاى بــنج كـارايى مسدل WOFOST را بالاتر از /9 هبيان كردند.

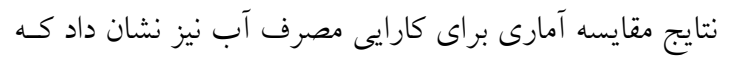

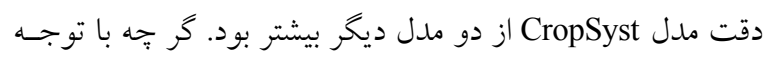

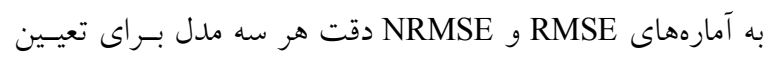
كارايى مصرف آب بسيار كم بود. اين نتايج بـا توجسه بــه مقـادير

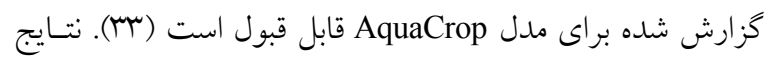

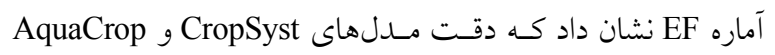

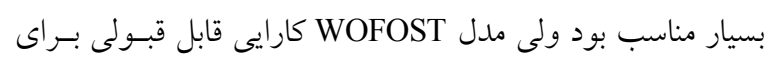

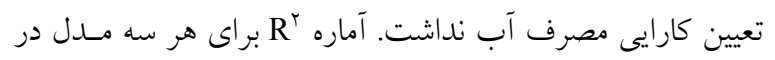

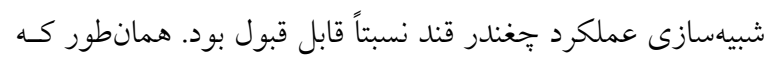

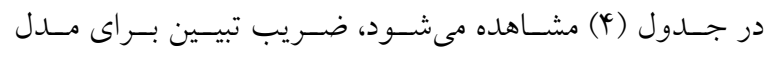
CropSyst

\section{نتيجه گيرى}

نتايج نشان داد كه در ارزيابى مــلهاى AquaCrop، WOFOST

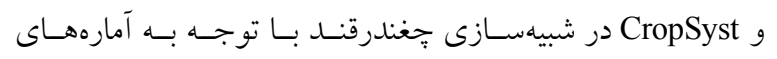
NRMSE و هM سه مدل دقت قابل قبولى داشـتند. لسيكن

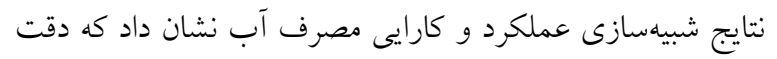

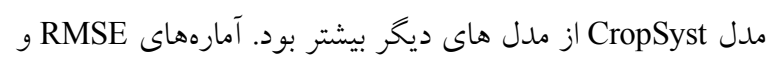

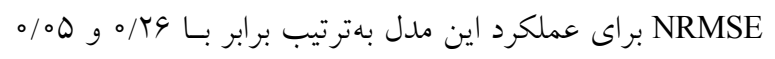

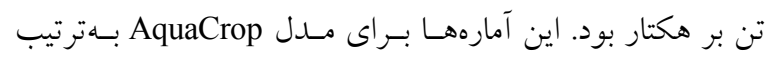

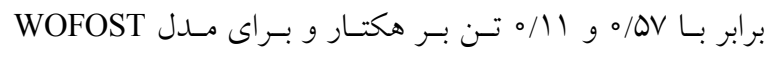

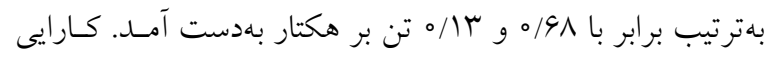

تن بر هكتار بود. مقدار NRMSE براى ايسن سـه مــدل بـهـترتيب

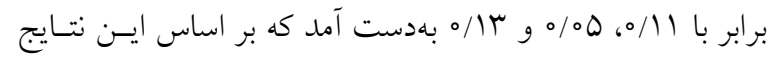

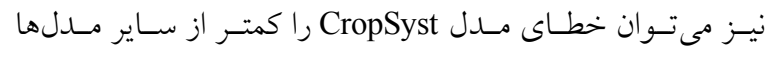

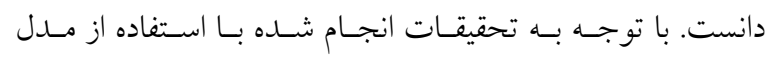

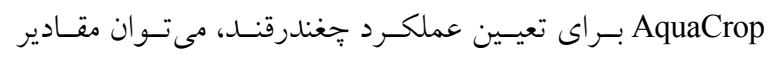

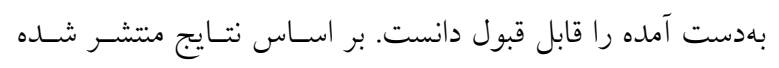

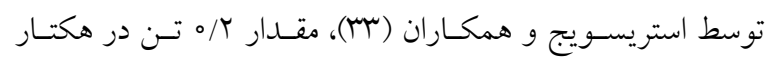
براى آماره RMSE مناسب است. على شيرى و همكـاران (1) نيـز

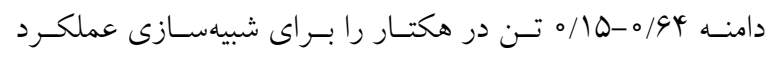
جغندرقند توسط مدل AquaCrop بيان كردند. درحالى كه مالك و

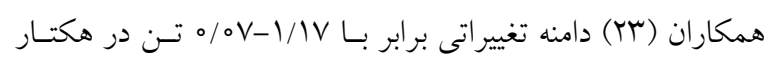

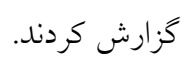

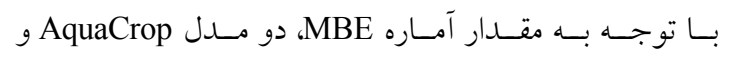

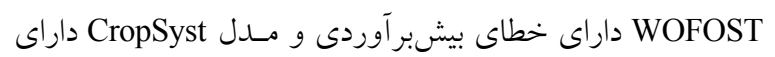

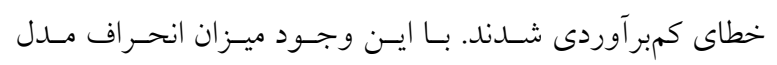
CropSyst نتايج بسيارى از يزوهشخران نشان داده است كه مدل AquaCrop

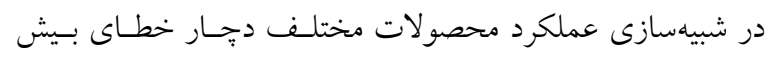

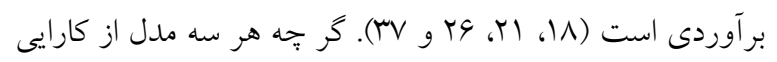

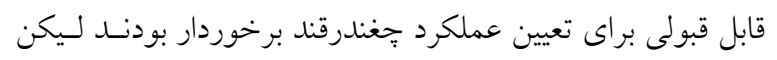

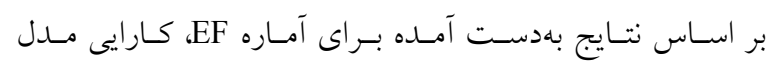

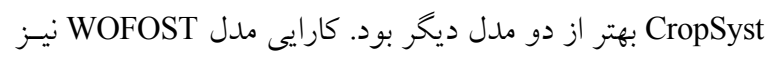

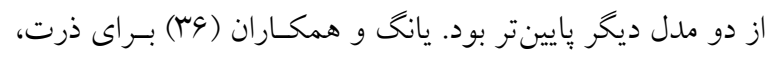

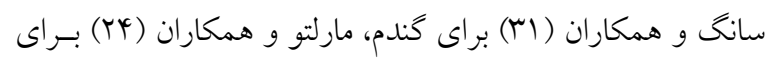




$$
\begin{aligned}
& \text { هر سه مدل براى شبيهسازى عملكرد نيز در حد قابل قبولى بود و كارايى مصرف آب با كاربرد مدل WOFOST بـهترتيب برابـر بـا }
\end{aligned}
$$

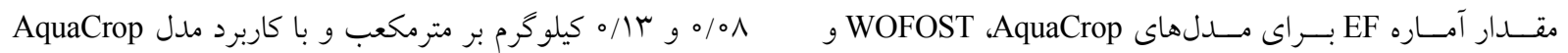

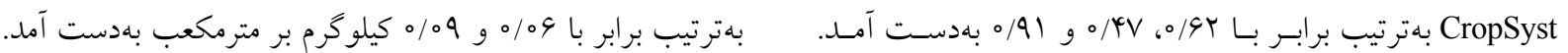

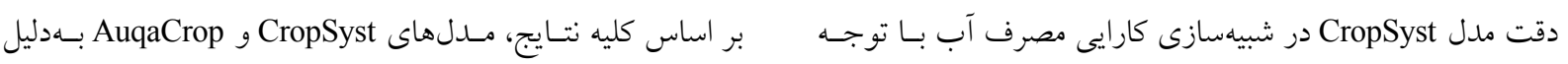

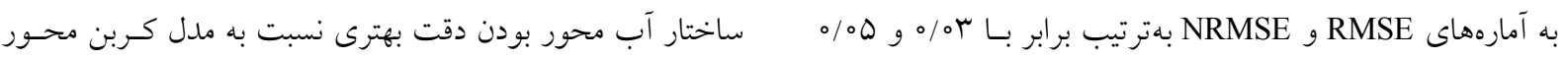

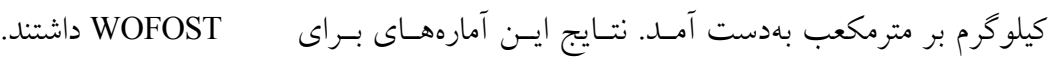

\section{منابع مورد استفاده}

1. Alishiri, R., F. Paknejad and F. Aghayari. 2014. Simulation of sugar beet growth under different water regimes and nitrogen levels by AquaCrop. Bioscience 4(4): 1-9.

2. Amiri, A., M. Kavoosi and F. Kaveh. 2009. Evaluation of crop growth models ORYZA2000, SWAP and WOFOST under different types of irrigation management, Food Engineering Research 10(3): 13-28. (In Farsi).

3. Andarziana, B., M. Bannayanb, P. Stedutoc, H. Mazraeha, M. E. Barati, M. A. Barati and A. Rahnama. 2011. Validation and testing of the AquaCrop model under full and deficit irrigated wheat production in Iran. Agricultural Water Management 100: 1-8.

4. Bellocchi, G., N. Silvestri, M. Mazzoncini and S. Menini. 2002. Using the CropSyst model in continuous rainfed maize (Zea mais L.) under alternative management option. Italian Journal of Agronomy 6:43-56.

5. Blum, F. A. 2009. Effective use of water (EUW) and not water-use efficiency (WUE) is the target of crop yield improvement under drought stress. Field Crops Research 112: 119-123.

6. Boogaard, H. L., C. A. Van Diepen, R. P. Rotter, J. M. C. A. Cabrera and H. H. Van Laar. 1998. WOFOST 7.1; user's guide for the WOFOST 7.1 crop growth simulation model and WOFOST Control Center 1.5 (No. 52). SCDLO.

7. Bouman, B. A. M., H. Van Keulen, H. H. Van Laar and R. Rabbinge. 1996. The "School of de Wit", crop growth simulation models: pedigree and historical overview. Agricultural System 52: 171-198.

8. Confalonieri, R., M. Acutis, G. Bellocchic and M. Donatelli. 2009. Multi-metric evaluation of the models WARM, CropSyst, and WOFOST for rice. Ecological Model 220: 1395-1410.

9. Confalonieri, R. and S. Bocchi. 2005. Evaluation of CropSyst for simulation the yield of flooded rice in northern italy. European Journal of Agronomy 23:315-326.

10. Ebrahimipak, N., Pazira, A., Kaveh, F., Abedi, M. J., Sabah Farashi, M. J., 2008, Effect of irrigation during different stages of sugar beet growth on its quantitative and qualitative yield. Research and Development 78: 63-73. (In Farsi).

11. Eitzinger, J., M. Trnka, J. Hosch, Z. Zalud and M. Dubrovsk. 2004. Comparison of CERES, WOFOST and SWAP models in simulating soil water content during growing season under different soil conditions. Ecological Model 171: 223-246.

12. Farahani, H. J., G. Izzi, P. Steduto and T. Y. Oweis. 2009. Parameterization and evaluation of AquaCrop for full and deficit irrigated cotton. Agronomy 101: 469-476.

13. Farre, F. and J. M. Faci. 2009. Deficit irrigation in maize for reducing agricultural water use in a Mediterranean environment. Agriculture Water Management 96: 384-394.

14. Garcia-Vila, M., E. Fereres, L. Mateos, F. Orgaz and P. Steduto. 2009. Deficit irrigation optimization of cotton with AquaCrop. Agronomy 101: 477-487.

15. Geerts, S. and D. Raes. 2009. Deficit irrigation as on-farm strategy to maximize crop water productivity in dry areas. Agricultural Water Management 96: 1275-1284.

16. Geerts, S., D. Raes, M. Garcia, R. Miranda and J. A. Cusicanqui. 2009. Simulating yield response to water of quinoa (Chenopodium quinoaWilld.) with FAO-AquaCrop. Agronomy 101: 499-508.

17. Gerik, T. J., W. D. Rosenthal and R. R. Duncan. 1988. Simulating grain yield and plant development of ratoon grain sorghum over diverse environments. Field Crops Research 19(1): 63-74.

18. Heng, L. K., T. C. Hsiao, S. Evett, T. Howell and P. Steduto. 2009. Validating the FAO AquaCrop model for irrigated and water deficient field maize. Agronomy 101(3): 488-498.

19. Hsiao, T. C., L. K. Heng, P. Steduto, D. Raes and E. Fereres. 2009. AquaCrop-Model parameterization and testing for maize. Agronomy 101: 448-459. 
20. Hussein, F., M. Janat and A. Yakoub. 2011. Simulating cotton yield response to deficit irrigation with the FAO AquaCrop model. Spanish Journal of Agricultural Research 9(4): 1319-1330.

21. Katerji, N., P. Campi and M. Mastrorilli. 2013. Productivity, evapotranspiration, and water use efficiency of corn and tomato crops simulated by AquaCrop under contrasting water stress conditions in the Mediterranean region. Agricultural Water Management 130: 14-26.

22. Kunz, R., R. Schulze, T. Mabhaudhi and O. Mokonoto. 2014. Modeling the potential impacts of climate change on yield and water use of sugarcane and sugar beet: preliminary results based on the AquaCrop model. South African Sugar Association 87: 285-289.

23. Malik, A., A. S. Shakir, M. Ajmal, M. Jamal Khan and T. Ali Kan. 2017. Canopy cover, biomass and root yield under different irrigation and field management practices in semi-arid regions of Pakistan. Water Resource Managment 31: 4275-4292.

24. Marletto, V., F. Ventura, G. Fontana and F. Tomei. 2007. Wheat growth simulation and yield prediction with seasonal forecasts and a numerical model. Agricultural Meteorology 147: 71-79.

25. Moriondo, M., F. Maselli and M. Bindi. 2007. A simple model of regional wheat yield based on NDVI data. European Journal of Agronomy 26: 266-274.

26. Mousavizadeh, S. F., T. Honar and S. H. Ahmadi. 2016. Assessment of the AquaCrop model for simulating canola under different irrigation management in a semiarid area. International Journal of Plant Production 10(4): 17356814.

27. Pakravan, M. and H. Mehrabi Boshrabadi. 2010. Estimating the eEconomic value of water in wheat production in Gorgan County, Water Research in Agriculture 4(6): 83-90. (In Farsi).

28. Raes, D., P. Steduto, T. C. Hsiao and E. Freres. 2012. Reference Manual AquaCrop, FAO, Land and Water Division, Rome, Italy.

29. Saadati, Z., N. Pirmoradian, A. Amiri and M. Rezaie. 2012. Evaluation of WOFOST model in simulating the performance of two varieties of rice under different irrigation regimes, Water Research in Agriculture 26(3): 323337. (In Farsi).

30. Salemi, H., M. A. Mohd Soom, T. S. Lee, S. F. Mousavi, A. Ganji and M. Kamil Yusoff. 2011. Application of AquaCrop model in deficit irrigation management of winter wheat in arid region. Spanish Journal of Agricultural Research SJAR 610: 2204-2215.

31. Song, Y. I., D. L. Chen and W. J. Dong. 2006. Influence of climate on winter wheat productivity in different climate regions of China. Climate. Research 32: 219-227.

32. Stockle, C. O. and R. L. Nelson. 1996. Cropsyst User's manual (Version 2.0). Biological Systems Engineering Department, Washington State University, Pullman, WA, USA.

33. Stricevic, R., M. Cosic, N. Djurovic, B. Pejic and L. Maksimovic. 2011. Assessment of the FAO AquaCrop model in the simulation of rainfed and supplementally irrigated maize, sugar beet and sunflower. Agricultural Water Managment 98: 1615-1621.

34. Todorovic, M., R. Albrizio, L. Zivotic, M. Abisaab and C. Stwckle. 2009. Assessment of AquaCrop, CropSyst and WOFOST models in the simulation of sunflower growth under different water regimes. Agronomy 101: 509-521.

35. Van Dam, J. C., J. Huygen, J. G. Wesseling, R. A. Feddes, P. Kabat, P. E. V. Van Walsum, P. Groenendijk and C. A. Van Diepen. 1997. Theory of SWAP Version 2.0, Report \#71. Department Water Resources. Wageningen Agricultural University.

36. Yang, H. S., A. Dobermann, J. L. Lindquist, D. T. Wolters, T. J. Arkebauer and K. G. Cassman. 2004. Hybridmaize-A maize simulation model that combines two crop modeling approaches. Field Crops Research 87: 131154.

37. Zeleke, K., D. Luckett and R. Cowley. 2011. Calibration and Testing of the FAO AquaCrop Model for Canola. Agronomy 103: 1610-1618.

38. Ziaie, GH., H. Babazadeh, H. Abbasi and F. Kaveh. 2014. Evaluation of the AquaCrop and CERES-Maize models in assessment of soil water balance and maize yield. Iranian Journal of Soil and Water Research 45(4): 435-445. (In Farsi). 


\title{
Assessment of AquaCrop, WOFOST and CropSyst models for Estimating Sugar Beet Yield under Water Deficit Conditions
}

\author{
N. A. Ebrahimipak ${ }^{1^{*}}$ and A. Egdernezhad ${ }^{2}$
}

(Received: December 17-2017 ; Accepted: May 5-2018)

\begin{abstract}
Sugar beet is one of the most important agricultural crops and its yield depends on irrigation water. Due to the impossibility of assessing the effect of all water amount strategies on sugar beet yield, it is necessary to use crop models such as WOFOST, AquaCrop and Cropsyst. In order to achieve this goal, a set of data collected from Shahrekord's Agricultural Research Station were used. Treatments consisted of irrigation water amount (in five levels: E0: 100\%, E1: 85\%, E2: 70\%, E3: 55\%, and E4: 30\%) based on crop evapotranspiration in different growth stages (T1: initial, T2: T2: mid-season, and T3: late season). The values of RMSE statistical criteria for the results of AquaCrop, WOFOST and CropSyst simulation were equal to $0.57,0.68$, and 0.26 ton.ha ${ }^{-1}$, respectively. NRMSE results were also obtained to be $0.11,0.13$, and 0.05 ton.ha $^{-1}$ for the mentioned crop mpdels, respectively. The results of the EF criteria revealed that CropSyst (0.91) had better efficiency, as compared to AquaCrop (0.62) and WOFOST (0.47). Regarding the results, it is suggested to use CropSyst to simulate sugar beet yield in similar conditions.
\end{abstract}

Keywords: Cropping Model. Radiation-Driven Model, Water-Driven Model

1. Department of Irrigation and Soil Physics, Soil and Water Research Institute, Agricultural Research, Education and Extension Organization (AREEO), Karaj, Iran.

2. Department of Water Sciences and Engineering, Ahvaz Branch, Islamic Azad University, Ahvaz, Iran.

*: Corresponding Author, Email: nebrahimipak@yahoo.com 